\title{
Dez Anos de Experiência com a Operação de Ross
}

\author{
Ten-Year Experience with the Ross Operation
}

\author{
Francisco Diniz Affonso da Costa, Elaine Welk Lopes Pereira, Luiz Eduardo Barboza, Hermínio Haggi Filho, Claudinei \\ Collatusso, Carlos Henrique Gori Gomes, Sérgio Augusto Veiga Lopes, Evandro Antônio Sardetto, Andréa Dumsch de \\ Aragon Ferreira, Marise Brenner Affonso da Costa, Iseu Affonso da Costa \\ Aliança Saúde Santa Casa - PUCPR, Curitiba, PR
}

Objetivo: Avaliar os resultados tardios de 10 anos com a operacão de Ross, analisando a sobrevida, incidência de reoperações e desempenho tardio do auto-enxerto pulmonar e homoenxerto da reconstrução da via de saída do ventrículo direito.

Métodos: Entre maio/1995 e fevereiro/2005, 227 pacientes com média de idade de 29,1 \pm 11 anos foram submetidos à operação de Ross. A etiologia prevalente foi a moléstia reumática em $61 \%$ dos casos. O auto-enxerto foi implantado com a técnica de substituição total da raiz em 202 casos, com cilindro intra-luminal em 20 e de forma subcoronariana em 5 . A reconstrução da via de saída do ventrículo direito foi feita de forma convencional, com homoenxertos criopreservados $(\mathrm{n}=$ 160), com extensão proximal de pericárdio no homoenxerto $(n=41)$ e com homoenxertos decelularizados $(n=26)$. O tempo de seguimento pós-operatório variou de 1 - 118 meses ( média= 45,5 meses).

Resultados: A mortalidade imediata foi de 3,5\% e a sobrevida tardia foi de 96,9\%, aos 10 anos. Não houve episódio de tromboembolismo, constatando-se apenas dois casos de endocardite. Onze pacientes foram reoperados, por problemas envolvendo o auto e/ou homoenxerto, progressão de doença reumática mitral e insuficiência coronariana iatrogênica. Após 10 anos, 96,4\% e 96,2\% dos pacientes estavam livres de reoperação no auto-enxerto e no homoenxerto, respectivamente. Não foi observada dilatação tardia dos auto-enxertos.A reconstrução da via de saída do ventrículo direito com homoenxertos decelularizados diminuiu de forma significativa a incidência de gradientes tardios.

Conclusão: Os resultados tardios com a operação de Ross demonstraram excelente sobrevida tardia e baixa incidência de reoperações e morbidade tardia. Consideramos este procedimento a melhor opção no tratamento cirúrgico da valvopatia aórtica em crianças e adultos jovens.

Palavras-chave: Auto-enxerto, operação de Ross, substituição da valva aórtica.

Objective: To evaluate the 10-year outcomes of the Ross Operation, analyzing survival rate, incidence of reoperations, and late performance of pulmonary autografts and homografts in the reconstruction of the right ventricular outflow tract.

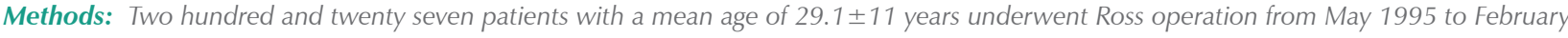
2005. The most prevalent etiology was rheumatic disease in $61 \%$ of the cases. Autografts were implanted using the total root replacement technique in 202 cases, with intraluminal cylinder in 20, and in the subcoronary position in 5. The right ventricular outflow tract was conventionally reconstructed with cryopreserved homografts $(n=160)$, with proximal extension of the homograft with pericardium $(n=41)$, and with decellularized homografts $(n=26)$. The postoperative follow-up ranged from 1 to 118 months (mean $=45.5$ months).

Results: Hospital mortality was 3.5\%, and long-term survival was $96.9 \%$ at ten years. No episodes of thromboembolism and only two cases of endocarditis occurred. Eleven patients underwent reoperation because of problems related to the auto and/or homograft, progression of rheumatic mitral valve disease, and iatrogenic coronary insufficiency. After 10 years, 96.4\% and $96.2 \%$ of the patients were free from reoperation in the autograft and homograft groups, respectively. No late autograft dilatation was observed. Reconstruction of the left ventricular outflow tract with decellularized homografts significantly reduced the incidence of gradients on late follow-up.

Conclusion: Late outcomes with the Ross Operation were associated with an excellent long-term survival and a low incidence of reoperations and late morbidity. We consider this procedure the best option for the surgical treatment of aortic valve disease in children and young adults.

Key words: Autografts, Ross operation, aortic valve replacement. 


\section{Artigo Original}

O substituto valvar aórtico ideal ainda é bastante controverso; entretanto, muitos consideram a operação de Ross como a melhor opção, especialmente em crianças e adultos jovens $s^{1,2}$. Dentre as vantagens do auto-enxerto pulmonar, encontram-se a durabilidade, o desempenho hemodinâmico fisiológico com preservação do mecanismo normal de abertura e fechamento valvar, a ausência de complicações tromboembólicas, baixa incidência de complicações infecciosas, além do potencial de crescimento, quando implantado em crianças. Essas vantagens têm sido confirmadas pelos resultados clínicos de médio e longo prazos em diversas séries ${ }^{3,4}$.

Por outro lado, a operação é tecnicamente mais complexa e sujeita à crítica de poder criar uma doença em duas valvas, no paciente com doença original em apenas uma. Além disso, variações na técnica da operação podem resultar em diferentes tipos de complicações com grande impacto nos resultados ${ }^{5}$.

Os resultados de longo prazo dos casos pioneiros de Ross refletem, em sua maior parte, a experiência com o implante do auto-enxerto pulmonar em posição subcoronariana ${ }^{6}$. Entretanto, na era atual, a técnica mais empregada tem sido a de substituição total da raiz aórtica, pela maior facilidade em se obter, consistentemente, um enxerto geometricamente alinhado e competente ${ }^{3}$.

Apesar da capacidade de adaptação da valva e da parede arterial pulmonar ao regime pressórico da circulação sistêmica, existe preocupação crescente de que o auto-enxerto pulmonar esteja sujeito a dilatação progressiva com formação de aneurisma da neo-aorta, e prolapso e insuficiência valvar concomitantes ${ }^{7,8}$. Além disso, a incidência de degeneração e disfunção do homoenxerto valvar implantado na via de saída do ventrículo direito, também pode aumentar a morbidade tardia, sujeitando os pacientes à necessidade de reoperações ${ }^{9,10}$.

O objetivo deste trabalho foi reavaliar, após dez anos de experiência, os resultados tardios com a operação de Ross, na qual foi empregada, preponderantemente, a técnica de substituição total da raiz aórtica, e, diferentemente de outras séries, em uma população com predomínio da moléstia reumática como etiologia da doença valvar. Foram avaliados os desempenhos funcionais tardios tanto dos auto-enxertos pulmonares como dos homoenxertos valvares empregados para a reconstrução da via de saída do ventrículo direito.

\section{Métodos}

Entre maio/1995 e fevereiro/2005, 227 pacientes foram submetidos a substitutição da valva aórtica pelo auto-enxerto pulmonar, no Serviço de Cirurgia Cardíaca da Aliança Saúde Santa Casa - PUCPR. Cento e sessenta e um pacientes $(71 \%)$ eram masculinos e a idade variou de 5 a 56 anos (média= $29,1 \pm 11$ anos), sendo que 35 pacientes tinham idade inferior a 18 anos. A etiologia mais freqüente da doença valvar foi a moléstia reumática em 140 casos (61\%), sendo que 15 pacientes apresentavam disfunção mitral importante associada. Dez pacientes apresentavam endocardite bacteriana na valva nativa ou em prótese valvar e quatro tinham aneurisma da aorta ascendente. Trinta e quatro pacientes já haviam sido submetidos a uma ou mais operações anteriores na valva aórtica sendo, plastia valvar aórtica em 14, plastia valvar mais ressecção de membrana subvalvar em 7 e prótese biológica em 13. Alguns dados clínicos e de exames complementares encontram-se listados na tabela 1.

Todas as operações foram realizadas pelo mesmo cirurgião e a técnica operatória foi detalhadamente descrita em publicações anteriores ${ }^{11}$. Entretanto, alguns detalhes técnicos relevantes para a correlação com eventuais disfunções do auto-enxerto e/ou do homoenxerto valvar são aqui revistos.

As operações foram feitas com circulação extracorpórea, hipotermia moderada de $30-32^{\circ} \mathrm{C}$ e proteção miocárdica com cardioplegia sanguínea gelada intermitente nos óstios coronarianos. O tempo de clampeamento aórtico foi de $104 \pm 22 \min (\min =69, \max =175)$ e o de circulação extracorpórea de $137 \pm 26 \min (\min =92, \max =230)$.

A técnica mais freqüentemente empregada foi a da substituição total da raiz aórtica em 202 casos, enquanto a técnica do cilindro intra-luminal (inclusão) foi usada em 20 pacientes e o implante subcoronariano em cinco.

Durante o preparo do auto-enxerto, foi deixada uma borda muscular de apenas 2-3 $\mathrm{mm}$ abaixo do plano valvar.

\begin{tabular}{|c|c|c|}
\hline Dados & $\mathbf{n}$ & $\%$ \\
\hline \multicolumn{3}{|l|}{ Lesão valvar } \\
\hline Eao & 56 & $(24,6)$ \\
\hline lao & 108 & $(47,5)$ \\
\hline DLAo & 63 & $(27,9)$ \\
\hline \multicolumn{3}{|l|}{ Etiologia } \\
\hline Reumática & 140 & $(61,6)$ \\
\hline Congênita & 53 & $(23,3)$ \\
\hline Degenerativa & 11 & $(4,8)$ \\
\hline Disfunção de prótese & 13 & $(5,7)$ \\
\hline Endocardite & 10 & $(4,6)$ \\
\hline \multicolumn{3}{|l|}{ Classe funcional } \\
\hline I & 22 & $(9,7)$ \\
\hline II & 150 & $(66,1)$ \\
\hline III & 48 & $(21,1)$ \\
\hline IV & 7 & $(3,0)$ \\
\hline \multicolumn{3}{|l|}{ Operação } \\
\hline Primária & 193 & (85) \\
\hline Reoperação & 34 & (15) \\
\hline \multicolumn{3}{|l|}{ Fração de ejeção } \\
\hline$>50 \%$ & 198 & $(87,2)$ \\
\hline $35-50 \%$ & 24 & $(10,6)$ \\
\hline$<35 \%$ & 5 & $(2,2)$ \\
\hline \multicolumn{3}{|c|}{$\begin{array}{l}\text { EAo- estenose aórtica; IAo- insuficiência aórtica; DLAo- dupla lesão } \\
\text { aórtica; } n=\text { número; } \%=\text { percentual. }\end{array}$} \\
\hline $\begin{array}{r}\text { Tabela } 1 \text { - Dados clínic } \\
\text { op }\end{array}$ & ciente & etidos a \\
\hline
\end{tabular}


Para a anastomose proximal, foi empregada a técnica de pontos separados, tomando-se o cuidado de passar os pontos junto à base das cúspides valvares. Independente da técnica empregada, a anastomose proximal foi sempre intra-anular, de forma que o anel aórtico nativo desse sustentação para o auto-enxerto pulmonar.

Quando empregada a técnica de substituição total da raiz aórtica, a anastomose proximal foi sempre reforçada em toda a sua circunferência com um tira de teflon ou de pericárdio bovino, tentando prevenir qualquer dilatação futura do anel aórtico. Da mesma forma, qualquer discrepância de diâmetro, proximal ou distal, foi sempre ajustada para compatibilizar as dimensões do auto-enxerto pulmonar com as do anel aórtico e da aorta ascendente. Em pacientes com discreta dilatação anular foi realizada a plicatura dos triângulos intercomissurais $(n=8)$ e, nos casos com anuloectasia mais acentuada, foi feita a redução externa do anel aórtico, com tira de teflon $(n=14)$. Já nos casos de hipoplasia do anel aórtico, foi feita a sua ampliação pela técnica de Mannouguian $(n=6)$ ou pela técnica de Ross-Konno, em cinco ocasiões ${ }^{12,13}$. A aorta ascendente foi ampliada em cinco casos de hipoplasia e, mais freqüentemente, foi reduzida por ressecção triangular em cunha, de porção da sua parede, em 18 pacientes com dilatação. Nos casos com aneurisma da aorta ascendente, o auto-enxerto foi estendido com um tubo de dacron até à porção inicial do arco aórtico. Em nenhum caso, a anastomose distal foi reforçada com tiras de teflon ou pericárdio bovino.

O auto-enxerto pulmonar foi sempre orientado de forma que o seu seio mais fino e desprovido de revestimento pericárdico fosse posicionado para o seio coronariano esquerdo, tendo dessa forma algum suporte das estruturas cardíacas posteriores à aorta ascendente.

Para a reconstrução da via de saída do ventrículo direito, os pacientes foram divididos em três grupos, dependendo da técnica operatória empregada ou método de preservação do enxerto. No grupo 1 ( $n=160)$, a reconstrução da via de saída foi feita com homoenxertos valvares frescos ou criopreservados suturados proximal e distalmente, sem a interposição de qualquer tipo de material protético. No grupo $2(n=41)$, a reconstrução da via de saída do ventrículo direito foi feita com homoenxertos criopreservados; entretanto, a anastomose proximal foi feita com a interposição de um remendo de pericárdio bovino ou pericárdio autólogo imerso em glutaraldeído, de forma a alongar o homoenxerto e evitando qualquer tensão nas anastomoses ou corpo do homoenxerto. Já o grupo $3(n=26)$ foi constituído por pacientes cuja via de saída do ventrículo direito foi reconstruída com homoenxertos valvares descelularizados. A técnica de implante, nesse grupo, foi semelhante à do grupo 1.

Procedimentos associados foram necessários em 28 pacientes: plastia mitral em 15, ressecção de aneurisma de aorta ascendente em 4, correção de CIV em 3 e revascularização do miocárdio, com enxerto venoso para a coronária direita, em casos de disfunção ventricular direita por hipofluxo coronariano, em 6 casos.

Nenhum paciente fez uso de anticoagulantes, e a prescrição de medicamentos cardiotônicos ou para insuficiência cardíaca ficou a critério do cardiologista de referência. A observação de complicações pós-operatórias foi feita de acordo com diretrizes bem estabelecidas ${ }^{14}$.

Todos os pacientes realizaram ecocardiograma transtorácico mono e bidimensional com Doppler, antes da alta hospitalar, e foram orientados para repetir esse exame no $6^{\circ}$ e $12^{\circ}$ mês de pós-operatório e depois anualmente. Foram anotadas as dimensões sistólica e diastólica do ventrículo esquerdo, assim como as espessuras da sua parede posterior e septal, sendo o cálculo da massa ventricular esquerda estimado pela formula, $\mathrm{MVE}=0,80 \times 1,05 \times[$ (Septo+Parede Posterior+Dimensão Sistólica VE) ${ }^{3}$ - Dimensão Sistólica $\left.\mathrm{VE}^{2}\right]$.

Os gradientes transvalvares, no auto-enxerto pulmonar e no homoenxerto da via de saída do ventrículo direito, foram calculados pela equação modificada de Bernoulli. O grau de insuficiência valvar foi estimado pela largura do jato de regurgitação na via de saída do ventrículo esquerdo, conforme descrito por Perry, e graduado como ausente, trivial, leve, moderado ou importante ${ }^{15}$. Utilizando a metodologia de Roman e cols., foram medidas as dimensões do autoenxerto pulmonar no nível anular, dos seios de Valsalva e na junção sinotubular ${ }^{16}$. Na avaliação ecocardiográfica tardia dos gradientes pulmonares e das dimensões do auto-enxerto pulmonar, foram considerados apenas os exames realizados pelo ecocardiografista de nossa instituição, que foram feitos de forma normatizada por um único operador.

O levantamento dos dados clínicos de pós-operatório tardio e a realização de ecocardiograma de controle foram feitos de forma dirigida, por três médicos, em nossa instituição, entre julho de 2004 e fevereiro de 2005. Cento e dez pacientes $(50,2 \%)$ vieram a nossa instituição e realizaram entrevista, exame clínico e ecocardiograma de controle. Em 61 pacientes $(27,8 \%)$, pudemos obter informações clínicas e do ecocardiograma atualizado, por meio de entrevista com o paciente e/ou cardiologista de referência, enquanto que em outros 31 casos (14,1\%) somente as informações clínicas puderam ser obtidas. Dezessete pacientes (7,7\%) não puderam ser contactados e foram considerados perdidos de seguimento. O tempo de seguimento total variou de 1 a 118 meses (média $=45,5$ meses).

Para a comparação dos gradientes pulmonares tardios entre os três grupos analisados, foi usado o teste não paramétrico de Kruskal-Wallis, dada a ausência de simetria dos dados e da homogeneidade das variâncias. Na análise dos fatores de risco para o desenvolvimento de gradientes pulmonares tardios, foi utilizado o teste não paramétrico de Mann-Whitney. As curvas atuariais de sobrevidade e livres de eventos foram feitas usando-se o método de Kaplan-Meier.

\section{Resultados}

A mortalidade hospitalar foi de 3,5\% (8/227). As causas foram a síndrome de baixo débito em 2 casos, hemorragia intra-operatória incontrolável em 2, fibrilação ventricular irreversível no pós-operatório imediato, lesão de artéria circunflexa anômala, lesão do primeiro ramo septal e angulação da coronária esquerda, em 1 caso cada.

Houve cinco óbitos tardios. Quatro foram súbitos, nos $1 ㅁ, 2^{\circ}, 4^{\circ}$ e $36^{\circ}$ meses, enquanto que o quinto óbito foi decorrente de endocardite do homoenxerto direito, aos 4 


\section{Artigo Original}

anos de evolução. Nos três primeiros pacientes que faleceram subitamente, a evolução clínica era bastante satisfatória e não havia condições clínicas que indicassem a ocorrência de eventos desfavoráveis. Já o paciente que faleceu subitamente no $36^{0}$ mês, era um caso de estenose aórtica e subaórtica congênita, com 4 operações prévias, bloqueio átrio-ventricular total e dependente de marcapasso cardíaco, que veio a falecer no 3 o ano de pós-operatório de uma operação de Ross-Konno. A sobrevida atuarial tardia foi de 96,9\%(LC95\%= 94,2\% - 99,6\%) aos 10 anos, quando considerados apenas os óbitos tardios e de 93,5\% (LC95\%= 90,1\% - 97,0\%), quando incluída a mortalidade hospitalar (fig. 1).

Dos 197 pacientes com evolução clínica conhecida, 181 encontram-se em classe funcional I e 15 em classe funcional II. Um paciente, operado com insuficiência aórtica IAo e miocardiopatia dilatada, continua com disfunção ventricular esquerda acentuada e apresenta-se atualmente em classe funcional III.

Não foi detectado nenhum caso de tromboembolismo no seguimento tardio. Endocardite bacteriana ocorreu duas vezes: uma no homoenxerto da via de saída do ventrículo direito, causando um dos óbitos tardios e outra no autoenxerto pulmonar que, apesar de ter sido erradicada com emprego de antibióticos, resultou em insuficiência valvar importante, por perfuração de uma das cúspides valvares, sendo necessária a reoperação. Nos 10 pacientes que foram operados por endocardite infecciosa, não houve recidiva.

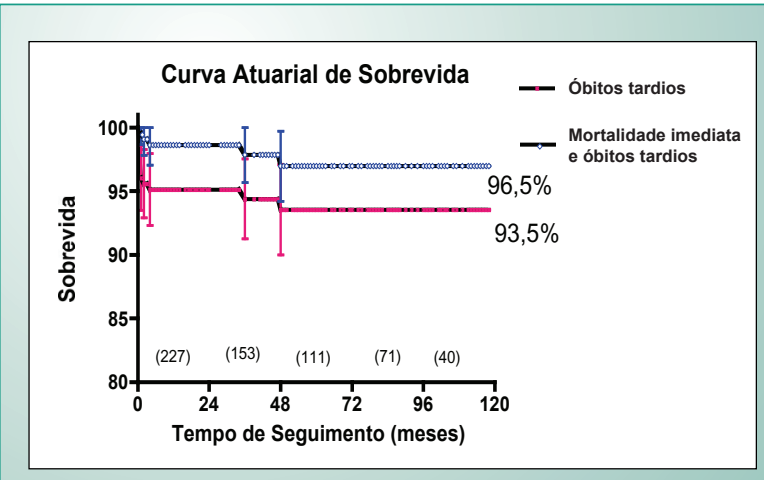

Fig. 1 - Curva atuarial de sobrevida em 227 pacientes submetidos à operação de Ross.

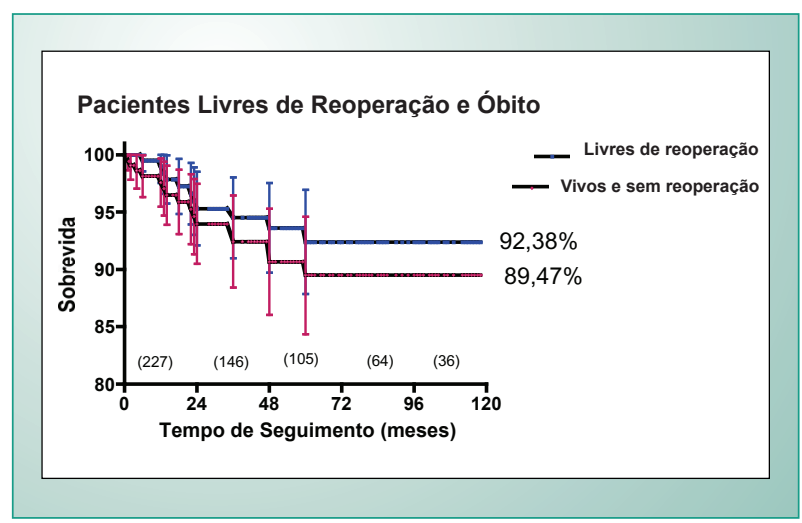

Fig. 2 - Curva atuarial demonstrando a probabilidade dos pacientes estarem livres de reoperação e vivos sem reoperação.
No período de seguimento, houve 11 reoperações, as quais estão listadas na tabela 2. O intervalo entre a operação primária e a reoperação variou de 6 a 60 meses. Dois pacientes foram reoperados com disfunção simultânea do auto e do homoenxerto valvar; três pacientes apresentavam disfunção do auto-enxerto pulmonar; dois do homoenxerto valvar direito; dois foram operados por progressão de doença mitral reumática; um paciente necessitou de revascularização do miocárdio por lesão ostial da coronária esquerda; e um paciente com endocardite tricúspide, que se estendeu para o anel do auto-enxerto pulmonar, necessitou de substituição aórtica e tricúspide. Não houve mortalidade nas reoperações. A probabilidade de os pacientes estarem livres de reoperação foi de 92,3\% (LC95\%= 87,8\% - 96,8\%) após 10 anos de evolução. Já a probabilidade de os pacientes estarem vivos e sem reoperação aos 10 anos, foi de 89,4\% (LC95\% = 84,3\% - 94,5\%) (fig. 2).

Em seis pacientes, foi necessária a substituição do autoenxerto pulmonar, conforme demonstra a tabela 3.

Em quatro desses casos, houve disfunção primária com insuficiência do auto-enxerto. Três foram operados com a técnica de implante subcoronariano e um com a técnica de inclusão. A causa de disfunção foi por problema técnico em dois casos, seqüela de endocardite bacteriana em um e auto-enxerto inapropriado em outro. Todos tiveram seus auto-enxertos pulmonares substituídos por homoenxertos aórticos criopreservados.

Importante salientar que, nenhum paciente operado com a técnica de substituição total da raiz aórtica necessitou de reoperação por disfunção primária do auto-enxerto pulmonar.

Um paciente desenvolveu endocardite bacteriana na valva tricúspide, a qual se estendeu para a tira de teflon, em torno do auto-enxerto pulmonar, com formação de importante abcesso para-valvar. Apesar de o auto-enxerto pulmonar não estar afetado pelo processo infeccioso e de ser normofuncionante, este foi lesado durante o debridamento dos tecidos infectados, sendo o paciente submetido a próteses biológicas, em posições aórtica e tricúspide.

Um paciente apresentou pseudo-aneurisma na linha de sutura proximal do auto-enxerto pulmonar com o anel aórtico, o qual pôde ser corrigido de forma direta, sem necessidade de substituição valvar.

\begin{tabular}{|ll|}
\hline Causa da reoperação & Casos \\
\hline Disfunção auto + homoenxerto & 2 \\
\hline Disfunção primária auto-enxerto & 2 \\
\hline Pseudo aneurisma do auto-enxerto & 1 \\
\hline Disfunção do homoenxerto & 2 \\
\hline Progressão de doença mitral & 2 \\
\hline Lesão ostial da coronária esquerda & 1 \\
\hline Endocardite tricúspide e aórtica & 1 \\
\hline Tabela 2 - Causas de reoperação em 227 pacientes submetidos \\
\hline
\end{tabular}




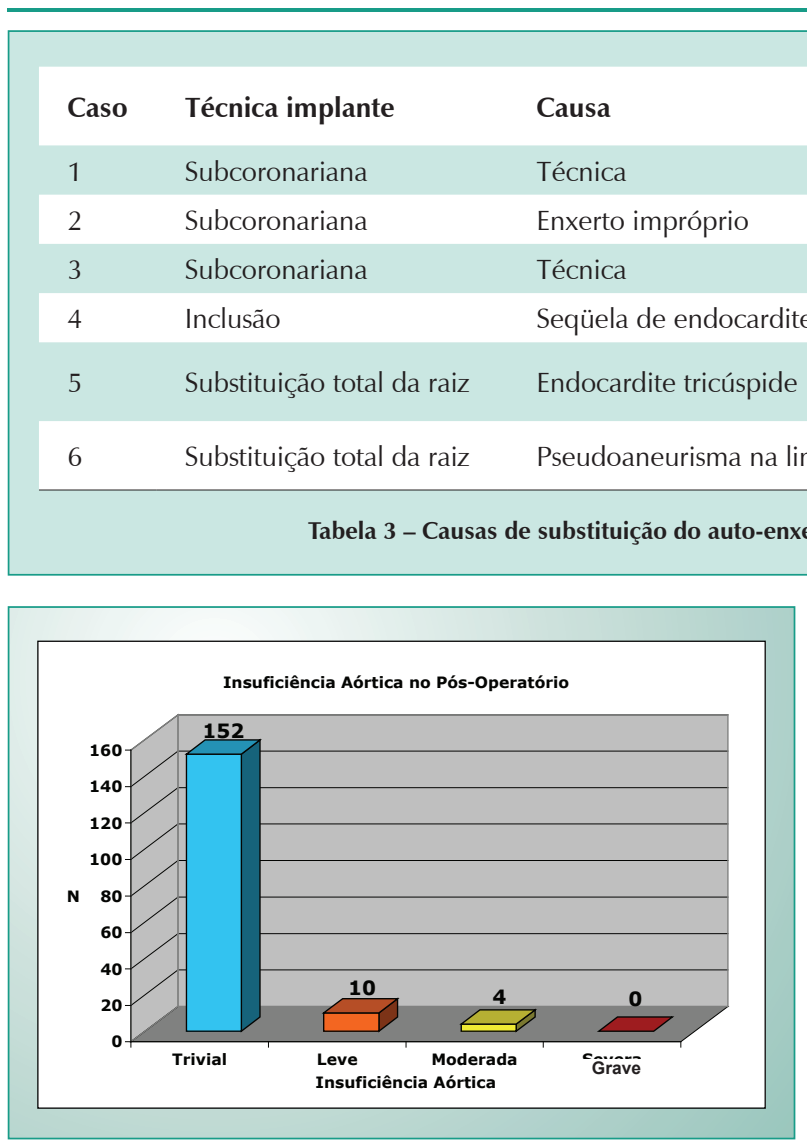

Fig. 3 - Insuficiência aórtica tardia.

Na última avaliação ecocardiográfica, 152 auto-enxertos pulmonares estavam competentes ou com insuficiência trivial, 10 apresentavam insuficiência leve, enquanto que quatro pacientes apresentavam insuficiência valvar moderada (fig. 3).

Três deles foram operados em 1995, eram reumáticos e os auto-enxertos foram implantados com a técnica de substituição total da raiz. No primeiro caso, a insuficiência valvar já havia sido graduada como moderada no $1^{\text {o }}$ ano de evolução, mantendo-se inalterada até o nono ano de seguimento. No segundo paciente, existe forte suspeita de novos surtos reumáticos pois, apesar do desenvolvimento de insuficiência moderada no auto-enxerto pulmonar, a progressão da valvopatia mitral foi ainda mais acentuada. No terceiro paciente, o auto-enxerto pulmonar apresentava insuficiência leve, no $3^{\circ}$ ano de evolução, progredindo para moderada, no 9o ano de seguimento tardio.

Um outro paciente, com aneurisma da aorta ascendente, valva aórtica bivalvular e dilatação acentuada do anel valvar aórtico, apresenta insuficiência valvar moderada do autoenxerto desde o $6^{0}$ mês de pós-operatório, mas continua estável até o segundo ano de seguimento.

A probabilidade de os pacientes estarem livres de reoperação, no auto-enxerto pulmonar, foi de 96,4\%(LC95\%= $93,6 \%-99,2 \%)$ aos 10 anos de evolução, enquanto que $89 \%$ (LC95\%= 79,6\% - 93,6\%) estão livres de reoperação e com o auto-enxerto normofuncionante (fig. 4).

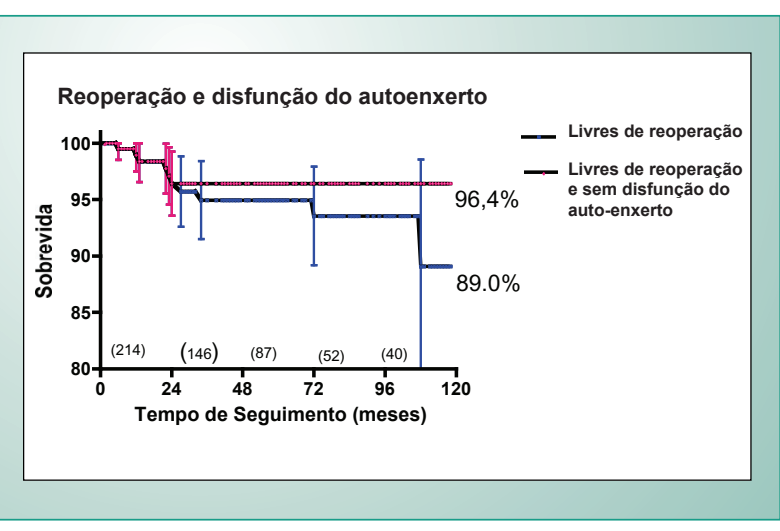

Fig. 4 - Curva de probabilidade de estarem livres de reoperação e/ ou insuficiêcia aórtica.

Os gradientes nos auto-enxertos pulmonares foram consistemente baixos, tanto na fase imediata como tardiamente. Na última avaliação ecocardiográfica, a média dos gradientes instantâneos máximos foi de $8 \pm 3,2 \mathrm{mmHg}$ $(\min =2, \max =32) . E m$ apenas dois casos, os gradientes foram maiores que $20 \mathrm{mmHg}$. No primeiro, o gradiente residual de $24 \mathrm{mmHg}$ se encontra na via de saída do ventrículo esquerdo, em um paciente com estenose aórtica e subaórtica congênita, apesar de uma ampliação do tipo Ross-Konno. O segundo caso se deve a surto reumático recidivante, com o paciente tendo o diagnóstico atual de DLAo ( gradiente = $32 \mathrm{mmHg}$ ) e DLMi moderadas, após 9 anos de evolução. Em decorrência do bom desempenho hemodinâmico dos autoenxertos, a massa ventricular esquerda reduziu de $288 \pm 45 \mathrm{~g}$ no pré-operatório para 197士39g tardiamente.

As dimensões do auto-enxerto no nível anular, dos seios de Valsalva e da junção sinotubular, nos 110 pacientes com ecocardiograma de controle tardio realizados em nossa instituição, encontram-se relacionadas na tabela 4. Esses exames foram realizados após um tempo de seguimento médio de 41 meses $(\min =2, \max =114)$. Não foram observadas dilatações aneurismáticas no auto-enxerto, sendo a maior dimensão observada de 4,2 e 4,3 cm nos seios de Valsalva e junção sinotubular, respectivamente.

Quatro pacientes foram reoperados, para substituir o homoenxerto valvar na via de saída do ventrículo direito. Em todos, as cúspides valvares estavam morfologicamente 


\section{Artigo Original}

\begin{tabular}{|lll|}
\hline Local da medida & Média \pm DP & Mín - máx \\
$\varnothing$ anular & $2,58 \pm 0,39 \mathrm{~cm}$ & $1,8-3,8 \mathrm{~cm}$ \\
$\varnothing$ seio de Valsalva & $3,31 \pm 0,58 \mathrm{~cm}$ & $2,0-4,2 \mathrm{~cm}$ \\
$\varnothing$ junção sinotubular & $3,37 \pm 0,55 \mathrm{~cm}$ & $1,9-4,3 \mathrm{~cm}$ \\
$\varnothing=$ diâmetro, DP- desvio-padrão, mín = mínimo, máx $=$ \\
máximo. \\
\hline \multicolumn{2}{|c|}{$\begin{array}{l}\text { Tabela 4 - Dimensões ecocardiográficas tardias no auto- } \\
\text { enxerto pulmonar }\end{array}$} \\
\hline
\end{tabular}

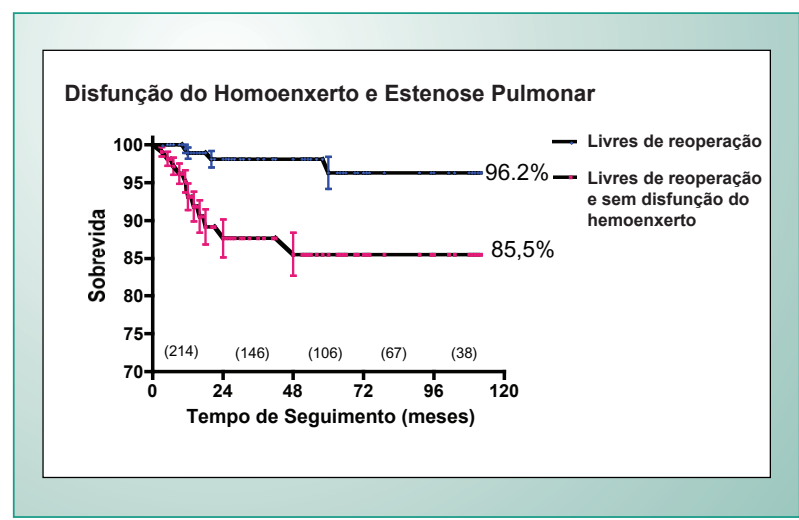

Fig. 5 - Curva de probabilidade de estarem livres de reoperação e de estenose do homoenxerto valvar direito.

normais; entretanto, havia importante reação fibrótica perivascular com retração acentuada e compressão extrínseca da parede arterial do conduto, causando estenose tubular difusa.

Além disso, dez pacientes, embora assintomáticos, demonstraram gradientes instantâneos máximos superiores a 40 mmHg na avaliação ecocardiográfica tardia. Em 8 deles, esses gradientes já haviam sido detectados nos primeiros dois anos de evolução pós-operatória, e se mantiveram inalterados ou com pequena progressão nos anos subsequentes. A probabilidade de os pacientes estarem livres de reoperação no homoenxerto valvar direito foi de 96,2\% (LC95\% = 94,1\% - 98,3\%) aos 10 anos de evolução, e 85,5\% (LC95\%= $82,9 \%$ - 88,3\%) estão livres de reoperação e com gradientes instantâneos máximos $\leq 40 \mathrm{mmHg}$ (fig. 5).

A técnica de reconstrução e/ou o método de preservação dos homoenxertos influenciaram de forma significativa os gradientes tardios encontrados na via de saída do ventrículo direito. No grupo 1 (Homoenxertos convencionais, sem extensão com pericárdio) a média dos gradientes instantâneos máximos foi de $24,2 \pm 17,7 \mathrm{mmHg}$, sendo que 9 pacientes $(13,4 \%)$ tinham gradiente maior que $40 \mathrm{mmHg}$. Já no grupo 2, (Homoenxertos convencionais, com extensão proximal feita com pericárdio) o gradiente instantâneo máximo foi de $17,2 \pm 11,8 \mathrm{mmHg}$, sendo que apenas 1 paciente $(4,1 \%)$ teve gradiente superior a $40 \mathrm{mmHg}$. No grupo 3, (Homoenxertos decelularizados) o gradiente instantâneo máximo foi de $10,7 \pm 4,4 \mathrm{mmHg}$, e o maior gradiente observado nesse grupo foi de $22 \mathrm{mmHg}$.

A análise univariada de fatores de risco para o desenvolvimento de gradientes elevados na via de saída

\begin{tabular}{|c|c|c|}
\hline Parâmetro & $\mathbf{p}$ & Significância \\
\hline $\begin{array}{l}\text { Decelularizado X } \\
\text { criopreservado }\end{array}$ & 0,0002 & $\mathrm{~S}$ \\
\hline $\begin{array}{l}\text { Decelularizado X } \\
\text { ampliação }\end{array}$ & 0,07 & NS* \\
\hline $\begin{array}{l}\text { Ampliação X } \\
\text { criopreservado }\end{array}$ & 0,06 & NS* \\
\hline Idade receptor $<20$ a & 0,03 & S \\
\hline Diâmetro homoenxerto & 0,41 & NS \\
\hline $\begin{array}{l}\text { Diâmetro homoenxerto / } \\
\text { Sup corp }\end{array}$ & 0,81 & NS \\
\hline Compatibilidade $\mathrm{ABO}$ & 0,09 & NS \\
\hline Idade do doador & 0,74 & NS \\
\hline $\begin{array}{l}\text { Idade doador - idade } \\
\text { receptor }\end{array}$ & 0,84 & NS \\
\hline \multicolumn{3}{|l|}{ * Significância estatística limítrofe. } \\
\hline $\begin{array}{r}\text { Tabela } 5 \text { - Fatores } \mathrm{d} \\
\text { homoer }\end{array}$ & $\begin{array}{l}\text { risco para } \\
\text { rto direito }\end{array}$ & enose do \\
\hline
\end{tabular}

do ventrículo direito demonstrou que, além do método de preservação dos homoenxertos, somente a idade do paciente menor que 20 anos esteve associada a estenoses tardias (tab. 5).

\section{Discussão}

Este estudo confirma que a operação de Ross é uma opção segura no tratamento cirúrgico de crianças e adultos jovens com valvopatia aórtica. A mortalidade hospitalar de 3,5\% nos parece bastante aceitável, especialmente se considerarmos a complexidade de nossos casos que incluiu pacientes mitro-aórticos, reoperações, aneurismas da aorta ascendente e endocardite bacteriana em valvas nativas e próteses valvares. Os riscos aumentados da operação de Ross, nestas circunstâncias, já foram bem discutidos ${ }^{5}$. Além disso, com maior experiência, foi possível melhorar ainda mais os resultados imediatos, havendo apenas um óbito hospitalar nos últimos oitenta casos operados.

As vantagens do emprego de um substituto valvar fisiológico ficaram evidenciadas na excelente sobrevida tardia, com ausência de eventos tromboembólicos mesmo sem terapia anticoagulante, baixa prevalência de complicações infecciosas e ampla recuperação funcional. Embora este estudo não seja comparativo, a maior sobrevida e melhor qualidade de vida nos pacientes submetidos à operação de Ross, quando comparados a outros substitutos valvares, já foram bem documentadas por outros ${ }^{2,17}$.

Apesar disso, a eventual necessidade de reoperações tardias, no auto e/ou homoenxerto valvar, continua sendo a maior preocupação, após o procedimento.

Mais recentemente, alguns autores relataram dilatação progressiva e insuficiência valvar aórtica como a principal causa de reoperações tardias em pacientes submetidos à operação 
de Ross com a técnica de substituição total da raiz. David e cols. analisaram 118 pacientes com tempo de seguimento médio de 44 meses, e encontraram 7 casos de insuficiência aórtica moderada ou grave, o que representou $92 \%$ de pacientes livres dessa complicação após 6 anos de evolução. Segundo os autores, pacientes com valva aórtica bivalvular e dilatação do anel aórtico constituem um subgrupo de pacientes mais propensos à dilatação tardia, pois apresentam alterações degenerativas mais acentuadas na parede da aorta ascendente e tronco pulmonar ${ }^{7}$. Na experiência de Elkins e cols., apenas $86 \%$ dos pacientes estavam livres de reoperação no auto-enxerto pulmonar, após 8 anos de evolução. Em 206 pacientes, com tempo de seguimento médio de 28 meses, foram necessárias 11 reoperações por insuficiência valvar, sendo a dilatação anular a causa mais freqüente. Por análise de regressão múltipla, encontraram que o diagnóstico préoperatório de estenose aórtica, esternotomia prévia e a técnica de substituição total da raiz foram fatores que diminuíram o risco do desenvolvimento de insuficiência valvar tardia ${ }^{5}$. Em contrapartida, na experiência de David e cols., a técnica de inclusão esteve associada a menos dilatação e insuficiência valvar do que à técnica de substituição total da raiz aórtica ${ }^{7}$. Kouchoukos e cols. reoperaram 11 auto-enxertos pulmonares dentre 119 pacientes com tempo de evolução médio de 51 meses. A maioria das reoperações ocorreu após o quinto ano de seguimento, sendo a dilatação progressiva do autoenxerto a causa mais comum. A probabilidade de os pacientes estarem livres de reoperação no auto-enxerto pulmonar foi de apenas $75 \%$, aos 10 anos. Como adendo em sua publicação, os autores informaram que sete pacientes adicionais foram reoperados por insuficiência aórtica, entre 5,5 e 11,5 anos de evolução ${ }^{8}$.

Nossos resultados não confirmam estas observações, com diferenças significativas não somente na prevalência, mas também no modo e relação temporal desta complicação. Nos 227 pacientes desta série, apenas 6 foram reoperados por disfunção no auto-enxerto, o que resultou em 96\% livres desse evento, aos 10 anos de evolução. Todas as reoperações foram necessárias antes do quinto ano de pós-operatório, sendo a falha técnica e a endocardite bacteriana as causas mais freqüentes de disfunção. É importante resaltar que, nenhum paciente operado com a técnica de substituição total da raiz aórtica foi reoperado nos primeiros dez anos. Dos quatro pacientes com IAo moderada tardia, nenhum apresenta dilatação anular e dos seios de Valsalva. Em dois de nossos casos, existe forte suspeita de novos surtos reumáticos como causa. Dados semelhantes aos nossos foram relatados por Carr-White e cols. que não evidenciaram dilatações superiores a $20 \%$ nos auto-enxertos de 49 pacientes, com períodos de observação de até 4 anos $^{18}$.

Diversos fatores podem influenciar a dilatação do autoenxerto pulmonar. Detalhes da técnica operatória tais como o implante intra-anular, a orientação espacial do enxerto, o reforço da sutura proximal com tiras de teflon ou pericárdio e correção de discrepâncias entre os diâmetros do auto-enxerto e a porção proximal e distal da aorta, não são realizados de forma uniforme entre os grupos cirúrgicos ${ }^{18-20}$. O adequado controle da pressão arterial, especialmente nos primeiros meses de pós-operatório, também pode ser significativo pois, nessa fase, a parede arterial pulmonar ainda não está adequadamente remodelada para suportar as pressões sistêmicas ${ }^{18}$.

Alguns estudos demonstraram que a parede arterial pulmonar de pacientes submetidos à operação de Ross apresenta, pré-operatoriamente, graus variados de deficiência e fragmentação de suas fibras elásticas, especialmente naqueles com valva aórtica bivalvular ${ }^{7,18}$. Na maioria das séries norte-americanas com a operação de Ross, a valva aórtica bivalvular é a etiologia mais freqüente, o que pode explicar a elevada incidência de dilatação tardia ${ }^{8}$. Nossa série é composta por $60 \%$ de doentes reumáticos, o que pode, pelo menos em parte, justificar a diferença nos resultados. Além disso, nosso tempo de seguimento médio de 44 meses pode ainda ser insuficiente para conclusões mais definitivas, o que enfatiza a necessidade de observação continuada nesses pacientes. As dimensões tardias aqui observadas sugerem que a geometria do auto-enxerto pulmonar é diferente da geometria da raiz aórtica nativa, sendo os diâmetros da junção sinotubular significativamente maiores do que os do nível anular. Nossas medidas ecocardiográficas foram superponíveis com as apresentadas por Carr-White e cols., e o fato de nosso tempo de seguimento ser bem superior, reforça a estabilidade e manutenção dos diâmetros do auto-enxerto ao longo do tempo ${ }^{18}$.

Outro aspecto relevante na operação de Ross refere-se ao potencial de crescimento, quando implantado em crianças ${ }^{21}$. Elkins e cols. analisaram 86 crianças submetidas a esta operação, demonstrando que o crescimento do auto-enxerto pulmonar foi proporcional ao desenvolvimento somático. Infelizmente, em nossa casuística, os dados referentes às dimensões anular, do seio de Valsalva e da junção sinotubular só foram elaborados na avaliação tardia, e não puderam ser sistematicamente comparados às dimensões pós-operatórias imediatas, o que nos impede de documentar o crescimento do auto-enxerto pulmonar em nossos pacientes pediátricos.

O envolvimento do auto-enxerto pulmonar em novos surtos de moléstia reumática já foi registrado por outros, sendo a provável causa de IAo moderada em dois de nossos casos. Por isso, a adequada profilaxia contra a doença deve ser feita de forma bastante rigorosa ${ }^{22}$.

Apesar de os homoenxertos valvares serem mais duráveis no lado direito da circulação, em decorrência do menor nível pressórico, também estão sujeitos à disfunção e necessidade de reoperações. A possibilidade de estenoses por retração da parede arterial do conduto ou localizada na região da anastomose distal é uma complicação bem estabelecida após a operação de $\operatorname{Ross}^{9,10}$.

Nossa experiência confirma a observação de outros, demonstrando que, apesar de os homoenxertos apresentarem desempenho hemodinâmico normal logo após a operação, freqüentemente existe discreto/moderado aumento dos gradientes em decorrência de retração fibrótica dos condutos. Este processo é precoce, ocorrendo nos primeiros dois anos de pós-operatório, e tende a estabilizar após esse tempo. Na maioria dos pacientes, os gradientes instantâneos máximos não ultrapassam $20 \mathrm{mmHg}$ e provavelmente sejam de pequena repercussão clínica. Entretanto, em alguns casos, a reação inflamatória é mais intensa, causando estenoses mais 


\section{Artigo Original}

importantes, podendo ser necessária a reoperação. Conforme já demonstrado em outros estudos, crianças e adolescentes apresentam maior risco para essa complicação, e isso também ocorreu em nossa série ${ }^{9,10,23}$.

Em 114 pacientes submetidos à operação de Ross por Ward e cols., 20\% apresentaram gradientes instantâneos máximos entre 25-40 mmHg no homoenxerto pulmonar e, em 4\% dos casos, esse gradiente foi maior do que $50 \mathrm{mmHg}$. Nos pacientes com estenose importante, os gradientes elevados foram detectados precocemente, entre os $4 \div-12^{\circ}$ meses de pós-operatório. Com auxílio da ecocardiografia, os autores concluíram que a maioria dos homoenxertos apresenta uma retração em torno de 15\%, sendo mais intensa em alguns casos. Em decorrência disso, recomendam o uso rotineiro de homoenxertos de maior diâmetro ${ }^{10}$. Entretanto, a nossa experiência confirma as observações de Moidl e cols. de que o uso de homoenxertos de grande diâmetro, por si, não foi suficiente para prevenir essa complicação ${ }^{24}$.

Carr-White e cols. fizeram minucioso estudo sobre o comportamento dos homoenxertos na operação de Ross, e detectaram gradientes pulmonares maiores que $30 \mathrm{mmHg}$ em $17 \%$ dos casos, sendo maior que $50 \mathrm{mmHg}$ em aproximadamente um terço destes. Nos pacientes que desenvolveram gradientes tardios, o estudo por ressonância magnética demonstrou não somente uma retração circunferencial nos condutos, mas também uma redução em torno de $40 \%$, no comprimento deles. Dentre as possíveis causas para essa retração, os autores sugerem que a tensão na parede do conduto possa liberar substâncias teciduais que estimulem uma reação fibrótica cicatricial ${ }^{9}$. Esses achados nos estimularam a fazer a modificação técnica na reconstrução da via de saída do ventrículo direito, alongando a porção proximal dos homoenxertos com remendos de pericárdio e aliviando a tensão no corpo do enxerto e nas anastomoses (grupo 2). Com isso, ocorreu diminuição dos gradientes tardios (grupo $1=24,2 \mathrm{mmHg}$ versus grupo $2=17,2 \mathrm{mmHg}$ ), sendo que somente um paciente assim operado teve gradiente maior que $40 \mathrm{mmHg}$. A diferença estatística entre os grupos foi limítrofe $(p=0,06)$, mas acreditamos que isso se deva ao número relativamente pequeno de casos estudados. A eficiência dessa manobra em reduzir os gradientes pulmonares tardios foi confirmada por Betchel e cols. ${ }^{25}$.

Apesar de os mecanismos causadores de estenose nos homoenxertos direitos não serem totalmente compreendidos, a ocorrência de febre pós-operatória e a presença de reação inflamatória crônica na adventícia com infiltrado linfocitário perivascular, em homoenxertos explantados, sugerem que fenômenos imunológicos sejam envolvidos ${ }^{9,10}$. Além disso, diversos estudos têm demonstrado que o emprego de homoenxertos valvares resulta em elevação de anticorpos HLA tipo I e II circulantes. Entretanto, a correlação entre o grau da rejeição imunológica e a disfunção tardia dos enxertos ainda é controversa ${ }^{26,27}$.

O processo de decelularização elimina as células endoteliais e intersticiais das cúspides e parede arterial dos homoenxertos, reduzindo acentuadamente seu potencial imunogênico, o que, pelo menos em teoria, poderia reduzir ou retardar a ocorrência das estenoses dos homoenxertos implantados na via de saída do ventrículo direito ${ }^{28,29}$. Na experiência de Betchel e cols., o emprego de homoenxertos decelularizados com a tecnologia Synergraft foi eficiente em reduzir a reação imunológica, mas não preveniu o desenvolvimento de gradientes tardios ${ }^{25}$.

Nossa experiência com homoenxertos decelularizados não está de acordo com a de Betchel e cols. possivelmente em decorrência das diferentes técnicas de decelularização ${ }^{25,30}$. Publicamos, recentemente, nossos resultados com homoenxertos decelularizados, que comprovam acentuada redução da antigenicidade e importante redução nos gradientes tardios ${ }^{31}$. Os pacientes do presente estudo (grupo 3) confirmam que, até 3 anos de evolução, os homoenxertos decelularizados apresentam desempenho hemodinâmico normal, sem elevação nos gradientes tardios. Esse dado é bastante animador visto que, em nossa experiência, as complicações dos homoenxertos direitos foram as mais prevalentes após a operação de Ross. Obviamente, resultados de prazo mais longo serão necessários para confirmar os méritos dessa nova tecnologia.

Os resultados com até 10 anos de evolução demonstraram que a operação de Ross esteve associada com excelente sobrevida tardia, baixa morbidade e excelente recuperação funcional. O auto-enxerto pulmonar teve pequena incidência de disfunção e não observamos dilatações tardias, durante o período de seguimento. Nenhum paciente operado com a técnica de substituição total da raiz aórtica foi reoperado por disfunção primária.Modificações na técnica operatória e/ou de preservação tecidual dos enxertos minimizaram os problemas relacionados à via de saída do ventrículo direito.

Em decorrência desses resultados, consideramos a operação de Ross como a melhor alternativa no tratamento cirúrgico da valvopatia aórtica de crianças e pacientes jovens.

\section{Potencial Conflito de Interesses}

Declaro não haver conflitos de interesses pertinentes.

\section{Referências}

1. Elkins RC, Lane MM, McCue C. Ross operation in children: late results. J Heart Valve Dis. 2001; 10(6): 736-41.

2. Concha M, Aranda PJ, Casares J, Merino C, Alados P, Munoz I, et al. Prospective evaluation of aortic valve replacement in young adults and middle-aged patients: mechanical prosthesis versus pulmonary autograft. J Heart Valve Dis. 2005; 14(1): 40-6.

3. Elkins RC, Knott-Craig CJ, Ward KE, Lane MM. The Ross operation in children:10-year experience.Ann Thorac Surg. 1998; 65(2): 496-502.

4. Bohm JO, Botha CA, Hemmer W, Starck C, Blumenstock G, Roser D, et al. Older patients fare better with the Ross operation. Ann Thorac Surg. 2003; 75(3): 796-801; discussion 802.

5. Elkins RC, Lane MM, McCue C. Pulmonary autograft reoperation: incidence and management. Ann Thorac Surg. 1996; 62(2): 450-5.

6. Chambers JC, Somerville J, Stone S, Ross DN. Pulmonary autograft procedure for aortic valve disease: long-term results of the pioneer series. Circulation. 1997; 96(7): 2206-14. 
7. David TE, Omran A, Ivanov J, Armstrong S, de Sa MP, Sonnenberg B, et al. Dilation of the pulmonary autograft after the Ross procedure. J Thorac Cardiovasc Surg. 2000; 119(2): 210-20.

8. Kouchoukos NT, Masetti P, Nickerson NJ, Castner CF, Shannon WD, DavilaRoman VG. The Ross procedure: long-term clinical and echocardiographic follow-up. Ann Thorac Surg. 2004; 78(3): 773-81; discussion.

9. Carr-White GS, Kilner PJ, Hon JK, Rutledge T, Edwards S, Burman ED, et al. Incidence, location, pathology, and significance of pulmonary homograft stenosis after the Ross operation. Circulation. 2001; 104(12 Suppl 1): I1620 .

10. Ward KE, Elkins RC, Overholt ED, Knott-Craig CJ, Razook JD, Lane MM, et al. Evaluation of cryopreserved homografts in the right ventricular outflow tract after the Ross procedure: intermediate-term follow up. J Heart Valve Dis. $1997 ; 6(2): 130-3$

11. Costa FDA, Poffo R, Matte E, Sardeto EA, Schneider RA, Ada EP, et al. Cinco anos de experiência com a operação de Ross. O que aprendemos? Rev Bras Cir Cardiovasc. 2000;15(2):109-28.

12. Manouguian S. Patch enlargement of the aortic valve ring. Description of a new operation method. An experimental and clinical study. Fortschr Med. 1983; 101(1-2): 31-3.

13. Hraska V, Krajci M, Haun Ch, Ntalakoura K, Razek V, Lacour-Gayet F, et al. Ross and Ross-Konno procedure in children and adolescents: mid-term results. Eur J Cardiothorac Surg. 2004; 25(5): 742-7.

14. Edmunds LH Jr, Clark RE, Cohn LH, Grunkemeier GL, Miller DC, Weisel RD. Guidelines for reporting morbidity and mortality after cardiac valvular operations. Eur J Cardiothorac Surg. 1996; 10(9): 812-6.

15. Perry GJ, Helmcke F, Nanda NC, Byard C, Soto B. Evaluation of aortic insufficiency by Doppler color flow mapping. J Am Coll Cardiol. 1987; 9(4): 952-9.

16. Roman MJ, Devereux RB, Kramer-Fox R, O'Loughlin J. Two-dimensional echocardiographic aortic root dimensions in normal children and adults. Am J Cardiol. 1989; 64(8): 507-12.

17. Carr-White GS, Glennan S, Edwards S, Ferdinand FD, Desouza AC, Pepper $J R$, et al. Pulmonary autograft versus aortic homograft for rereplacement of the aortic valve: results from a subset of a prospective randomized trial. Circulation. 1999; 100(19 Suppl.): II103-6.

18. Carr-White GS, Afoke A, Birks EJ, Hughes S, O'Halloran A, Glennen S, et al. Aortic root characteristics of human pulmonary autografts. Circulation. 2000; 102(19 Suppl 3): III15-21.

19. Hokken RB, Bogers AJ, Taams MA, Schiks-Berghourt MB, van Herwerden LA, Roelandt JR, et al. Does the pulmonary autograft in the aortic position in adults increase in diameter? An echocardiographic study. J Thorac
Cardiovasc Surg. 1997; 113(4): 667-74.

20. Sievers HH, Leyh R, Loose R, Guha M, Petry A, Bernhard A. Time course of dimension and function of the autologous pulmonary root in the aortic position. J Thorac Cardiovasc Surg. 1993; 105(5): 775-80.

21. Elkins RC, Knott-Craig CJ, Ward KE, McCue C, Lane MM. Pulmonary autograft in children: realized growth potential. Ann Thorac Surg. 1994; 57(6): 1387-93.

22. Pieters FA, Al-Halees Z, Hatle L, Shahid MS, Al-Amri M. Results of the Ross operation in rheumatic versus non-rheumatic aortic valve disease. J Heart Valve Dis. 2000; 9(1): 38-44.

23. Xie GY, Bhakta D, Smith MD. Echocardiographic follow-up study of the Ross procedure in older versus younger patients. Am Heart J. 2001; 142(2): 331-5.

24. Moidl R, Simon P, Kupilik N, Chevtchik O, Heinrich N, Moritz A, et al. Increased pulmonary flow velocities in oversized homografts in patients after the Ross procedure. Eur J Cardiothorac Surg. 1997; 12(4): 569-72; discussion 573 .

25. Bechtel JFM, Steinhardt MM, Schnidtke C, Brunswik A, Stierle U, Siever $\mathrm{HH}$. Evaluations of the Decellularized Valve Homograft (SynerGraftTM). J Heart Valve Dis. 2003;12:734-40 - in discussion.

26. Welters MIP, Oei FBS, Witvliet MD, Vaessen LMB, Dijkhuis AHC, Borges JJC, et al. A Broad and Strong Humoral Immune Response to Donor HLA after Implantation of Cryopreserverd Human Heart Valve Allografts. Human Immunology. 2002;63:1019-1025.

27. Dignan R, O’Brien M, Hogan P, Thornton A, Fowler K, Byrne D, et al Aortic valve allograft structural deterioration is associated with a subset of antibodies to human leukocyte antigens. J Heart Valve Dis. 2003;12(3):38290; discussion 390-1.

28. O’Brien MF, Goldstein S, Walsh S, Black, Elkins R, Clarke D. The synergraft valve: A new acellular (nonglutaraldehyde-fixed) tissue heart valve for autologous recellularization First Experimental Studies Before Clinical Implantion. Semin Thorac Cardiovasc Surg. 1999; 11:194-200.

29. Elkins RC, Lane MM, Capps SB, McCue C, Dawson PE. Hunoral Humora immune response to allograft valve tissue pretreated with an antigen reduction process. Semin Thorac Cardiovasc Surg. 2001;13(suppl I):82-6.

30. Kasimir MT, Rieder E, Seebacher G, Silberhumer G, Wolner G, Weigel G, et al. Comparision Comparison of different decellularization procedures of porcine heart valves. Int J Artif Organs. 2003;26:421-7.

31. Costa FDA, Dohmen PM, Duarte D, Glenn CV, Lopes SV, Haggi H, et al. Immunological and echocardiographic evaluation of decellularized versus cryopreserved allografts during the Ross operation. Eur J Cardiothorac Surg. 2005 27: 572-8. 